\title{
Improving the provision of pre-arrival information and support to international students via the use of online resources
}

\author{
Shelley Webster, University College London
}

\section{Acknowledgement}

This paper originated as a student project from the Post Graduate Certificate in Enhancing the International Student Experience.

\section{Introduction from Dr Dave Burnapp (Course Leader)}

From the position of an International Student Welfare Adviser at UCL, this article describes research into the effectiveness of previous pre-arrival information made available to new international students, and suggests an alternative structure which replaces general information with a more in-depth package, including online support utilising a number of different technologies. Importantly this allows students to enter into online communities even before their arrival.

\section{Abstract}

Rapid growth in international students studying in the UK has resulted in focus being placed upon the international student experience at all stages of the academic cycle. Particularly relevant is the pre-arrival stage, where the increased number of students from different countries means it is hard to provide comprehensive pre-arrival support to all new students. Traditional in-country pre-departure briefings are no longer financially or logistically viable and do not provide adequate support to all. This project aimed to develop a new approach to pre-arrival support, in the form of an 'online pre-departure briefing'. This would utilise both social and multi-media resources and could be adapted to work in other institutions. Measures were identified for gauging the success of the project, including data analysis, student feedback and student participation and the data was used to identify areas of strength and weakness and make recommendations for further improvements to either the current or adapted models.

Keywords: international students; pre-entry support; online support 


\section{Background}

UCL (University College London) continues to see growth in the number of international students coming to study at the institution each year. HESA (Higher Education Statistics Agency 2009/10) statistics show (HESA 2011) that for the year 2009/10 UCL had 8730 international students. This figure represents a 54\% increase in numbers since 2002/03 when the figure was 4723 . Internal data and analysis of the most recent ISB (summer wave 2010) data shows that these students are coming from a diverse range of places, with the student body currently representing over 140 different countries. In addition to this it can be seen that UCL is attracting increasing numbers of graduate taught students, with numbers increasing from 2035 in the 08/09 academic year to 2450 in the $09 / 10$ academic year, representing an increase of $20.39 \%$.

Rapid growth in international students studying in the UK has resulted in increased focus being placed upon the international student experience. In 2006 the second phase of the Prime Minister's Initiative (PMI) was launched with an aim of looking at the international student experience as a whole and the ways in which institutions could improve satisfaction levels. In response to this shift in focus UCL has undertaken a number of activities and projects aimed at assessing and subsequently improving the situation in terms of the international student experience at UCL. These include the following;

- Undertaking a report to audit the current provision of services to international students, and

- Formation of an International Student Experience Working Group tasked with formulating and implementing new initiatives.

In my role as International Student Welfare Adviser, I recently produced a report examining the international student experience as a whole and the current level of academic and welfare provision made available to international students at UCL. This involved interviewing key stakeholders in the international student experience (i.e. Dean of Students (Welfare), UCL Union Rights and Advice Centre etc), analysing the data and open comments from the International Student Barometer (ISB) and undertaking an audit of the information available to international students on the website. The findings of this are currently being used to identify areas in which improvement is needed and inform any recommendations made.

The report findings, combined with the increased diversity of international students and the growing number of taught international graduates (who have a shorter adjustment period and rely heavily on comprehensive pre-arrival support), have resulted in analysis of the level and type of pre-arrival information and support currently available to international students at UCL. This article reports on the project undertaken in direct response to this internal analysis. 


\section{Research aims}

In previous years the pre-arrival information and support available to international students at UCL has comprised of the following:

- Information made available on the International Office website in relation to immigration and visas, accommodation and UCL support services,

- Pre-departure briefings in select countries that have a large student base at UCL (China, Cyprus, Hong Kong, Kazakhstan, Malaysia, Singapore, Russia and Thailand), and

- Receipt by post of the general UCL publication 'Joining UCL'

Upon reviewing the provision I found that the information available on the website was rather generic and did not cover many essential topics, (highlighted by academics and students as being important in the earlier International Student Experience Report e.g. including academic matters and cultural adjustments) required in order to prepare students for the transition to studying and living in the UK. I found that this was also the case with the information included in the 'Joining UCL' booklet. This publication is a general publication aimed at all students and has very limited pre-arrival information tailored for international students making the transition to living and studying in London. In addition to the above I felt a large portion of students were missing out on vital pre-arrival support as a result of in-country provision only being provided to a select few, in countries where UCL traditionally recruits a high number of students. I found this particularly concerning as it is these students from the more remote countries, who do not have access to strong networks of peers prior to and upon arrival, who may need the most assistance and guidance.

In light of the above findings I have developed an alternative structure for providing pre-arrival information and support to new students. Under this new structure general information and in-country pre-departure briefings will be replaced with a more comprehensive and in-depth package of online support that utilises a number of different technologies. It is hoped that this will provide a high level of support to all international students.

As a result of developing these new online resources it is hoped that the following aims and objectives will be realised:

- international students will have access to more in-depth and comprehensive pre-arrival information on a broader range of topics,

- the online resources will provide support to all new international students and will not just focus upon countries that have a large community at UCL,

- use of online social communities will facilitate and encourage more students to meet each other prior to arrival, encouraging integration amongst country groups, 
- the orientation programme will be more widely promoted, and

- integration with UCL will begin prior to arrival as a result of increased and earlier communication from the International Office.

\section{Literature Review}

In light of the introduction of the second phase of the Prime Minister's Initiative there has been increased focus upon the International Student Experience in UK Higher Education. However, at the current time there is not a great deal of literature that is primarily concerned with discussing and analysing the different methods and importance of pre-arrival support. It is more likely that this aspect of the student experience will be touched upon in more wide reaching reports.

Two UK wide reports which have looked into this area have concluded that although students satisfaction levels for pre-arrival support are reasonably high $(80 \%>)$ there is still a lot of scope for institutions to improve (UKCISA 2004, UK HE International Unit 2010). The UKCISA 'Broadening Our Horizons' also highlights and reinforces the findings of the 1994 HEIST survey (Allen A \& Higgins T, 2004), that found that there was a direct correlation with students experiencing problems upon arrival in areas for which they felt 'ill-prepared' at the pre-arrival stage. This is especially the case in relation to immigration and accommodation issues. The reports have also highlighted the importance of pre-arrival information and support in relation to managing students' expectations and maintaining satisfaction levels.

In light of the above and the current volatile recruitment climate, which is seeing increasing global competition for international students from countries such as Singapore, Hong Kong and Malaysia (Middlehurst \& Woodfield, 2007) it is important that institutions see that in terms of pre-arrival information; 'the need for clear electronic and written communication is paramount', and it can not be seen as an 'optional extra' (UK HE International Unit 2010). If institutions wish to compete on a global scale, they will need to strive to enhance provision wherever possible.

In terms of the type of provision currently available the most recent UKCISA benchmarking of UK higher education institutions (UKCISA 2007) suggests that the majority provide pre-arrival information to students via handbooks $(95 \%)$ and on the institution website (89\%). 53\% also provide in-country events and $41 \%$ provide email bulletins. This benchmarking report was published in 2007 and at the current time UKCISA is undertaking another benchmarking exercise due to be reported later this year. This will provide useful data on if and how institutions have changed the approach in the increasingly competitive recruitment climate.

\section{Outline of Intervention}

In order to enhance and maximise the potential of providing an online pre-arrival resource the new package incorporates three different elements with the aim of improving the level and delivery of pre-arrival information, whilst also encouraging students to interact and become involved in the UCL community prior to arrival: 
- an in depth online information and advice website,

- an interactive element that utilises social networking sites, and

- a more pro-active and direct form of communicating with students in order to inform them of the resources

\section{Online information and advice website}

The website comprises of six different sections which provide the following information;

i) Information for offer holders section - This provides information on:

- Accommodation,

- UCL Support services,

- NHS and health services,

- Opening a bank account,

- Financial advice, and

- Academic transition

There is also a useful links section that directs students to external websites that may be of assistance.

ii) Immigration and visas - This section is dedicated to supplying information on the Points Based System and advises students on how to apply for a Tier 4 student visa or Student Visitor Visa. A frequently asked questions section is included.

iii) Travelling to UCL / UCL residences - As UCL does not offer a meet and greet service, detailed information on travelling from the main points of entry (Heathrow, Gatwick, Stansted, Luton Airport and Eurostar) to the main UCL campus and each individual UCL residence has been provided. This information includes a variety of travel options, information on cost and estimated journey times.

iv) Orientation and induction - Information is provided in relation to the International Student Orientation Programme, alongside details of when, how and where to enrol. A clear explanation of the process, including what documents to bring is also included.

v) UK Culture and London life - This section includes links to websites that provide information on the cultural aspects of living in the UK and the issue of 'Culture Shock'. Information is provided on London life including such aspects as travel, entertainment, places of worship, sports facilities and much more. There are also links to the different communities in London from around the world and where to find them. 
vi) Current student videos - A number of videos have been made available featuring current international students answering questions on their pre-arrival and arrival experiences at UCL. The videos comprise the following sections:

- Pre-arrival and travelling,

- Arrival,

- First days,

- Settling in,

- Social life, and

- Academic matters

\section{Social media - Facebook}

In addition to the dedicated website a facebook group for all new international students has been made available. Unlike the previous in-country events it is hoped that this will encourage students to meet each other and develop networks outside of their country groups prior to arrival, as opposed to forming tight country based networks, which was the case with the in-country events.

The Facebook group is also a platform for delivering up to date information to students on administrative processes, deadlines, upcoming events and useful preparation tools , for example Prepare for Success (UKCISA, 2011) and the International Student Calculator (UNIAID, 2011).

\section{Communicating with new students}

In order to maximise the number of students who utilise this pre-arrival package, changes have been made to the way in which students are contacted. Traditionally general pre-arrival information would be made available on the UCL website and all students would be sent a generic 'Joining UCL' booklet by post. No direct contact was made with international students to inform them of specialist information.

The following steps have been taken to increase the level and effectiveness of prearrival contact with new students:

i) students are to be contacted directly by email and informed of the online pre-arrival package, and

ii) a link to the website is to be included on the New Student website

\section{Research Methodology}

Obtaining feedback is essential in gauging how successful the online resources have been and to highlight were improvements need to be made in subsequent years. 
Evaluation of the online package of resources, online communities and increased prearrival communication has been undertaken in a variety of ways, using both qualitative and quantitative date in order to add depth to the findings. The different methods used were as follows;

\section{Ezine format emails}

All new international students have been contacted by email to inform them of the online pre-arrival package, International Student Orientation Programme and enrolment appointments. Each of these emails was sent in an ezine format, which meant that it was possible to track how many emails were successfully received, how many were then opened and how many students linked through to the new website for further information.

Through analysis of this data I will be able to evaluate the success of this method in relaying information to new students and gain insight into how many students are accessing the new online resources. It will also enable me to assess how accurate the electronic contact information is that we hold for students and will provide insight into whether improvements need to be made in this area.

\section{Google Analytics}

In addition to the use of ezine emails, Google analytics will be used to track the number of visits to the pre-arrival website. It will be possible to assess how successful the ezine emails have been in generating traffic to the site, as it will be possible to cross examine the number of hits on the site with the dates that the emails where sent out.

\section{Facebook data}

All students will be sent an email informing them about the Facebook group and in addition to this all students who sign up for the international student orientation programme will be sent an invite to join. It will be possible to analyse the success of this group by looking at the following:

- number of students who join,

- interaction between students on the comments wall,

- analysis of the different groups created and students involvement in them, and

- analysis of data from the online feedback questionnaire.

\section{Online feedback questionnaire}

To gain more insight into the levels of usage and usefulness of the different elements of the pre-arrival package, questions in relation to the package have been included in the International Student Orientation programme, online feedback questionnaire. The questionnaire required students to rate how good they found the different elements and provided an opportunity to leave open comments in relation to what they think 
worked well and where improvements could be made. Students were made aware of the questionnaire in the following ways;

i) advertisement at the International Student Orientation Programme welcome talks, and

ii) emails sent to all new students who attended the orientation programme asking them to complete the form

All those who completed the form were also entered into a prize draw in order to encourage participation.

\section{Analysis of Autumn 2010 International Student Barometer (ISB)}

Data from the autumn 2010 wave of the ISB will be used to gauge students' satisfaction levels in relation to pre-arrival information. Comparisons to earlier waves of the ISB will be made to see if there have been any significant improvements.

\section{Research findings}

\section{Ezine format emails and Google Analytics}

In total 4,114 ezine emails were sent to all new full degree and affiliate international students informing them about the pre-arrival website and Facebook group. Analysis of the ezine data shows that the open rate for these emails was $74 \%$, with $53 \%$ of these students immediately clicking through to the pre-arrival web link.

In addition to this analysis by Google Analytics shows that from the week of launch to the end of student orientation, the on-line pre-departure package attracted 30,000 views $(23,300$ unique views) fig 1 .

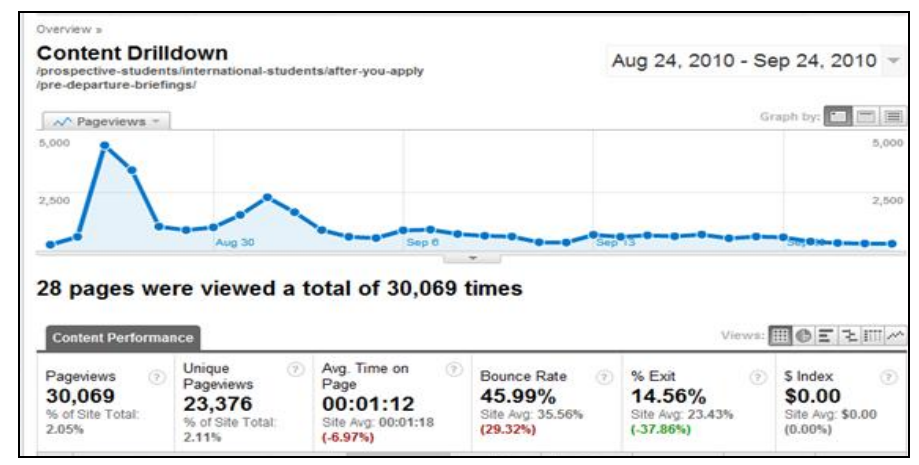

Fig 1 Number of views to the on-line pre-departure package website

It can also be seen that peaks in viewing correspond directly with the ezine emails being sent to students (4,531 page views, 26 August, Fig 2) and an email being sent to affiliate offer holders (2,292 page views, 1 September, Fig 3). 


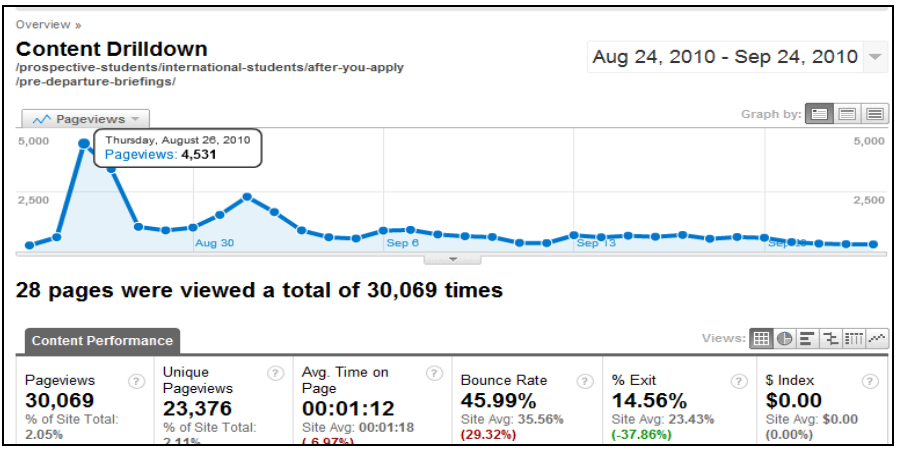

Fig 2 Correlation between promotional emails to UG and PG students and views to the website

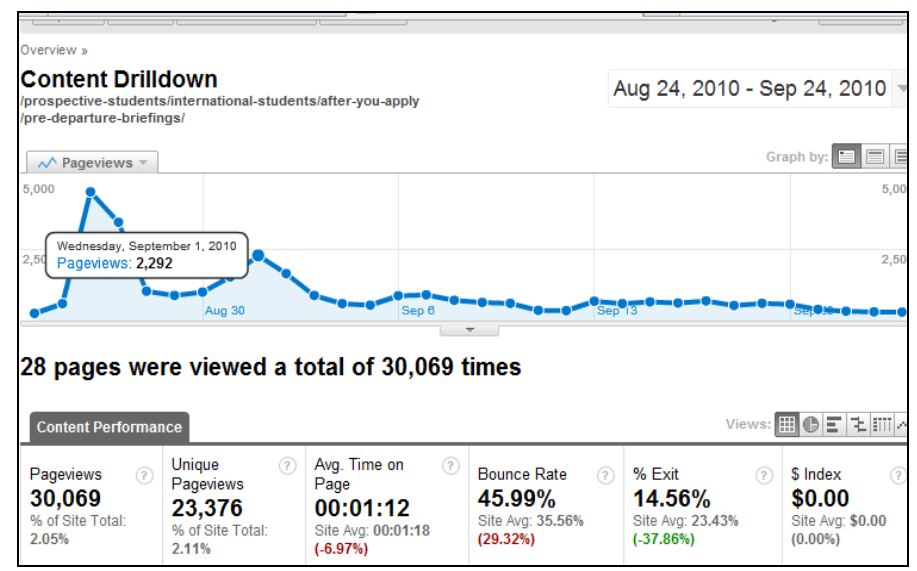

Fig 3 Correlation between promotional emails to affiliate students and views to the website

\section{Facebook data}

At its peak the Facebook group had 1800 members, which represents $44 \%$ of the number of new students who received an ezine email informing them about it. Analysis of the group shows that students used it in a number of different ways including

o to identify other students on their course or in their hall of residence,

○ to identify other students from their home country,

○ to look for students to travel to the UK with

○ to identify other students to find private accommodation with,

$\circ$ to meet with via to leaving their home country, and to

○ find out other students experiences of obtaining visas and housing allocations.

Further analysis of the success/usefulness of the Facebook group will be made by analysing students responses to the group in the online questionnaire. 


\section{Online feedback questionnaire}

In order to enable us to collect data on the experience of international students using the pre-arrival website and Facebook group an online feedback form was developed (See Annex 1). The form was completed by 845 (c. $28 \%$ of the number students who opened the ezine email and $30 \%$ of the students who attended the orientation programme- this is a very good participation rate) students which has provided us with a very good source of data to draw conclusions.

\section{Results}

Q1. Did you use the on line pre-departure package? How would you rate the information webpages?

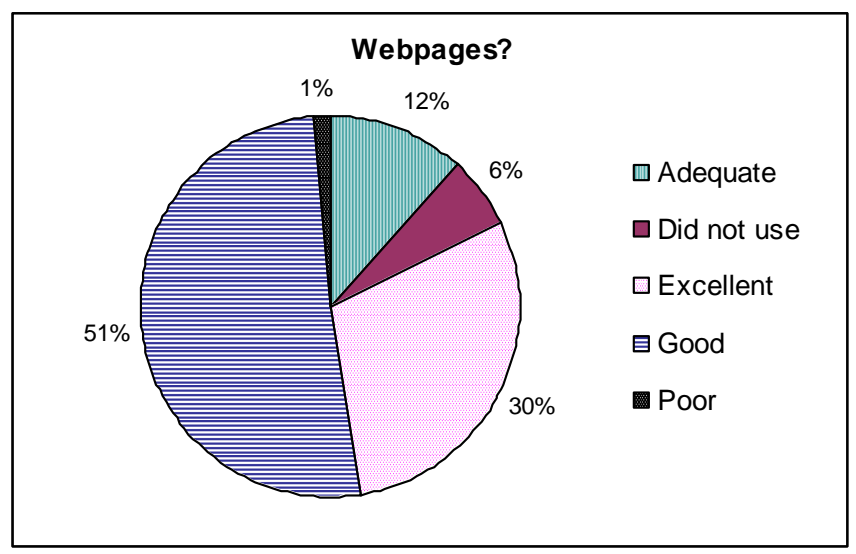

Fig 4 Satisfaction levels for the information webpages

$6 \%$ of respondents did not use the pre-departure website. However of those who did $86 \%$ rated it as either good or excellent.

Q2. How would you rate the Pre-departure videos?

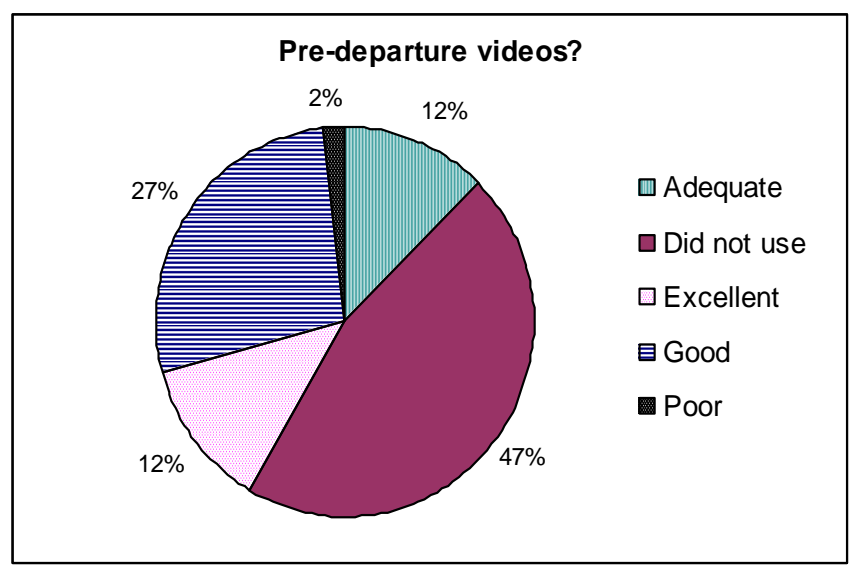

Fig 5 Satisfaction levels for the pre-departure videos

$47 \%$ of respondents did not use the pre-departure videos. Of those who did use them $67 \%$ found them either good or excellent.

Q3. How would you rate the Facebook site? 


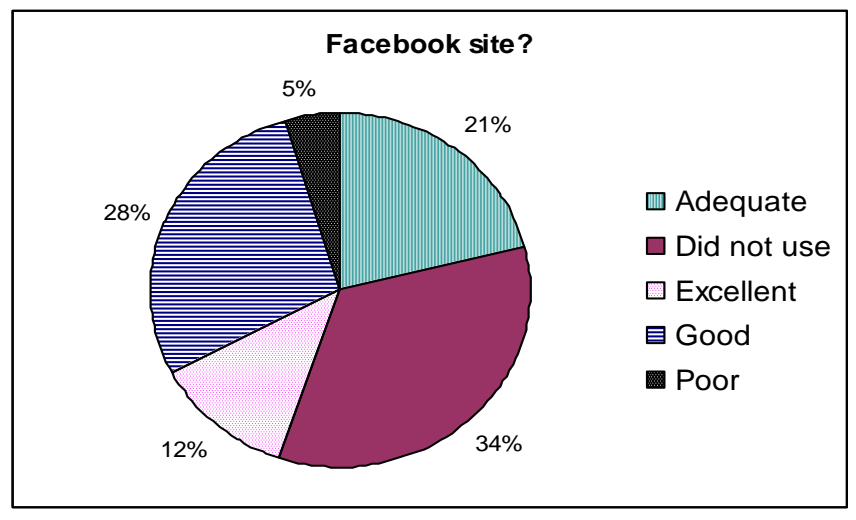

Fig 6 Satisfaction levels for the Facebook site

$34 \%$ of respondents did not use the facebook page. Of those who did $61 \%$ found them either good or excellent. It should be noted that in some countries (e.g. China) facebook is not available. In other countries different social networking sites are preferred. E.g. in Brazil 'Orkut' is the most popular.

Q4. How would you rate the directions to individual residences?

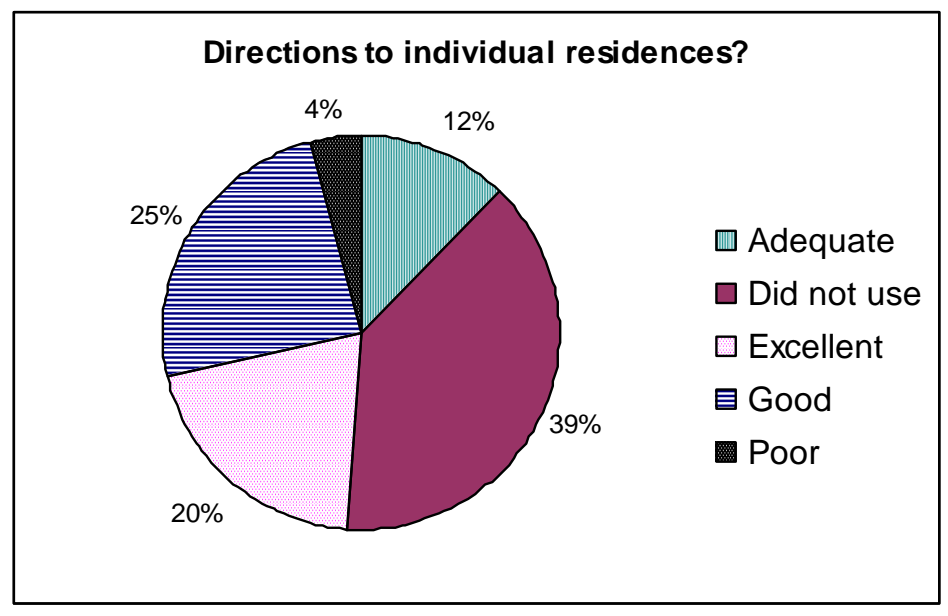

Fig 7 Satisfaction levels for the directions to individual residences

$39 \%$ of respondents did not use the directions to individual residences. Of those who did $74 \%$ found them either good or excellent.

\section{Autumn 2010 International Student Barometer (ISB)}

The ISB asks students about additional communication from the university received between accepting a place of study and arriving. In the autumn 2009 wave only $17 \%$ of international students stated that they had received any information further information from UCL. In the autumn 2010 wave this percentage has almost doubled to $30 \%$.

This suggests that the efforts made to improve the frequency and style of communication has been effective and an increasing numbers of students are receiving pre-arrival communications. 


\section{Discussion of findings}

\section{Effectiveness of improved communication}

Ezine data and data collected via Google Analytics suggests that the penetration of pre-arrival information this year has been significantly greater than previous arrangements (Fig 1) and that contacting students electronically is a very effective way of communicating information prior to arrival. Due to its instant nature it is much more effective then sending hard copy information that students have in the past reported to be delayed in the post or not arriving at all.

As a result of contacting students directly, more students have had access to the improved pre-arrival material. This is not only supported by the above data but also by the fact that increased numbers of students attended the International Student Orientation Programme (that was advertised in both the ezine and on the pre-arrival website) and further by the number of students who joined the Facebook group. The data from the online feedback questionnaire also supports the fact that a greater number of students had access to the pre-arrival materials as students from over 80 different countries took part.

\section{Usage and satisfaction rates}

In terms of providing an in-depth and comprehensive package of materials, of the students who completed the questionnaire $96 \%$ used the main information pages and of these, $86 \%$ rated the pages either good or excellent. This suggests that students found the materials helpful and that usage rates were high. Satisfaction and usage rates were also high (although not as high as 96\%) amongst students who utilised the videos, Facebook group and travel guides.

\section{Social networking to encourage integration}

Analysis of the data relating to the Facebook group suggests mixed success. On the one hand over 1800 students joined the group and there was frequent activity in terms of students contacting each other in relation to topics such as who is doing which course, finding housing, immigration problems and when people are travelling to the UK, to name just a few. Students were able to meet their peers outside of their country groups and form networks and friendships prior to arrival, something that was not possible under the previous arrangements.

However, one major draw back of using Facebook for this purpose is that there is a significant portion of students from certain countries (e.g. China) who can not access Facebook (BBC 2011) and in addition to this other countries use different social networking sites. For example in Brazil 'Orkut' is more popular (Comscore 2010). Thus resulting in limitations being placed on students being able to take that opportunity to socialise and form networks with other students. This is of particular concern for the integration of Chinese students, as traditionally this is a section of the student body that tend to stay within their own country group. 


\section{Comparative data}

The outcomes of the autumn wave 2010 International Student Barometer will complete the data analysis for this project. With this data I will be able to gain insight into student satisfaction levels for pre-arrival support and make direct comparison with satisfaction levels of previous years under the old arrangement. I will be able to identify more clearly where improvements have been made and where focus and resources may need to be directed in future years. This data will be analysed when it becomes available.

\section{Research reflections}

Upon re-examining the aims and objectives and comparing them to the research findings it can be seen that there are a number of ways in which the overall project can be seen as a success. However there are also someone aspects of the online resources that upon review do not appear to have worked entirely in the way that was hoped and overall there are a number of ways in which the resources and data analysis could be improved in future years.

\section{Successes}

Upon reflection it can be concluded that by incorporating email contact at a key point during the summer, was a very effective way of ensuring the objective of providing pre-arrival support to a much wider range of students was achieved. One particularly positive result of this being that there was a steep increase in the number of students who attended the orientation programme, which may be a direct result of better communication on the institution's behalf. This may be further improved by having earlier and more frequent communication with new students.

In addition to this, the incorporation of the use of a popular social networking site can be seen to have facilitated the aim of enabling and encouraging students to form networks with students across country groups. Thus providing a more accommodating environment for students to integrate prior too and upon arrival than the previous incountry arrangements permitted. However, upon reflection it can be seen that this method does have its draw backs, which will be discussed more fully in the 'failures' section.

Finally it can also be seen that the methods in which the data was subsequently collected have been effective and have enabled me to draw good conclusions on the overall effectiveness and success of the project. However, it should be noted here that most of the data collected was in fact qualitative data with only a small amount of quantitative data available. This is something that will be discussed further in the improvements section.

\section{Failures}

As previously mentioned the main area in which the current provision did not fully meet the objectives set out at the beginning was in relation to facilitating the process of cross country integration between students prior to arrival. Although to some degree this did take place, a number of factors, as discussed previously prevented this 
being available to all students. This is an area in which more thought needs to be given and where improvements must be made.

\section{Improvements}

As a result of the above reflections it has been possible to identify a number of ways in which this project can be built upon and improved. These are as follows;

- Earlier and more frequent communication via email, in order to reach more students, attract higher numbers of visits to the website and further the potential of student engagement in the first few weeks.

- The use of more social networking platforms to overcome the limitations seen with Facebook.

- Using more direct forms of feedback from students, including more detailed specific pre-arrival questionnaire, student discussion forums and focus groups.

- Improved promotion of the online resources by incorporating the following strategies;

i. A link to the website to be included in the 'Joining UCL' and 'Crucial' publications sent to all new students, and

ii. Individual departments to be made aware of the resource and to be encouraged to inform international students where possible.

\section{References}

Allen, A \& Higgins, T. (1994) 'Higher Education: The International Student Experience'. Leeds: HEIST, in UKCISA, (2004), 'Broadening Our Horizons: international students in UK universities and colleges'

BBC, (2011), Country Profile China, (online), Available at http://news.bbc.co.uk/1/hi/world/asia-pacific/country_profiles/1287798.stm\#media Accessed 01/06/2011

Comscore, (2010), Press release (online) Available at http://www.comscore.com/Press_Events/Press_Releases/2010/10/Orkut_Continues_to _Lead_Brazil_s_Social_Networking_Market_Facebook_Audience_Grows_Fivefold Accessed 01/06/2011

HESA, (2011), Available at: http://www.britishcouncil.org/eumd/statistics/ Accessed 01/06/2011

Middlehurst, R \& Woodfield, S. (2007) 'Responding to the Internationalisation agenda: Implications for institutional strategy'

UK HE International Unit, (2010), 'A Guide to Enhancing the International Student Experience' 
UKCISA, (2004), 'Broadening Our Horizons: international students in UK universities and colleges'

UKCISA, (2007), 'Benchmarking the Provision of Services for International Students in Higher Education Institutions'

UKCISA, (2011) Prepare for Success web tool (online), Available at http://www.prepareforsuccess.org.uk/ - Accessed 01/06/2011

UNIAID, (2011) International Student Calculator (online), Available at http://www.studentcalculator.org.uk/international/ - Accessed 01/06/2011

\section{About the author}

Shelley Webster is International Student Welfare Advisor at University College London

Email: shelley.webster@ucl.ac.uk 